\title{
RESULTADOS MATERNO-PERINATALES EN GESTANTES CON COVID-19 EN UN HOSPITAL NIVEL III DEL PERÚ
}

\author{
Carmen Dávila-Aliaga@1,2,a,b, Rosmary Hinojosa-Pérez(101,a,b, \\ Marcos Espinola-Sánchez 101,3,a,c, Elsa Torres-Marcos(10 1,a,b, Enrique Guevara-Ríos@14,4,a,d, \\ Ylia Espinoza-Vivas (101,a,b, Elina Mendoza-Ibañez (1),a,b, Claudia Saldaña-Díaz(11,a \\ 1 Instituto Nacional Materno Perinatal, Lima, Perú. \\ 2 Universidad Nacional Federico Villarreal, Lima, Perú. \\ 3 Universidad Privada del Norte, Lima, Perú. \\ 4 Universidad Nacional Mayor de San Marcos, Lima, Perú.

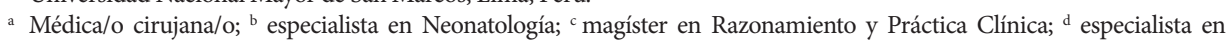 \\ Ginecología y Obstetricia.
}

\section{RESUMEN}

El presente estudio tuvo como objetivo describir los resultados materno-perinatales de gestantes con infección por SARS-CoV-2 identificadas antes del parto, en un hospital nivel III del Perú. Se evaluaron variables sociodemográficas, complicaciones obstétricas y morbilidades neonatales en los nacimientos ocurridos entre el 1 de abril y el 30 de junio de 2020, en el Instituto Nacional Materno Perinatal del Perú. Se registraron 43 recién nacidos, $93 \%$ de las madres fueron asintomáticas. Las complicaciones obstétricas más frecuentes fueron rotura prematura de membranas $(18,6 \%)$ y preeclampsia $(11,6 \%)$. El $65,1 \%$ de nacimientos fue por parto vaginal, solo uno de los recién nacidos presentó resultado positivo a la prueba de reacción en cadena de polimerasa con transcriptasa inversa (RT-PCR) para COVID-19, las comorbilidades de los recién nacidos fueron prematuridad (11,3\%), bajo peso al nacer $(9,3 \%)$, cuatro ingresaron a cuidados intermedios y dos a cuidados intensivos. Se concluye que el $2,4 \%$ de los recién nacidos hijos de madres con COVID-19 presentó prueba molecular positiva de RT-PCR, el 14\% de recién nacidos presentó morbilidad como prematuridad, bajo peso al nacer, sepsis y neumonía que requirió ventilación. La morbilidad neonatal se encontró en recién nacidos cuya prueba de RT-PCR fue negativa para COVID-19.

Palabras clave: COVID-19; Pandemias; Infección por Coronavirus 2019-nCoV; Infección por coronavirus; Embarazo; Recién nacido; Infante (Fuente: DeCS BIREME)

\section{MATERNAL-PERINATAL OUTCOMES IN PREGNANT WOMEN WITH COVID-19 IN A LEVEL III HOSPITAL IN PERU}

Citar como: Dávila-Aliaga C, Hinojosa-Pérez R, Espinola-Sánchez M, Torres-Marcos E, Guevara-Ríos E, Espinoza-Vivas Y, et al. Resultados materno-perinatales en gestantes con COVID-19 en un hospital nivel III del Perú. Rev Peru Med Exp Salud Publica. 2021;38(1):58-63. doi: https://doi. org/10.17843/rpmesp.2021.381.6358.

Correspondencia: Marcos Espinola Sánchez; Jr. Santa Rosa 941, Lima, Lima, Perú; marcosespinola.es@gmail.com

\begin{abstract}
The present study aimed to describe the perinatal outcomes of newborns of mothers with 2019 coronavirus infection identified before delivery in a level III hospital in Peru. Sociodemographic variables, obstetric complications, and neonatal morbidities were evaluated in the births that occurred between April 1 and June 30, 2020, at the National Maternal Perinatal Institute of Peru. 43 newborns were registered: $93 \%$ came from asymptomatic mothers, the most frequent obstetric complications were premature rupture of membranes (18.6\%) and pre-eclampsia (11.6\%), $65.1 \%$ of the births were vaginally, only one of the newborns had a positive result to RT-PCR for COVID-19, the comorbidities of the newborns were prematurity (11.3\%) and low birth weight (9.3\%); four were admitted to intermediate care and two to intensive care. It is concluded that $2.4 \%$ of newborns born to mothers with COVID-19 presented positive molecular test of RT-PCR, $14 \%$ of newborns presented morbidity as prematurity, low birth weight, sepsis and pneumonia that required ventilation. Neonatal morbidity was found in newborns whose RT-PCR test was negative for COVID-19.
\end{abstract}

Keywords: Covid-19; Pandemics; Coronavirus-2019-nCoV; Coronavirus infection; Pregnancy; Newborn; Infants (Source: MeSH NLM)

\section{INTRODUCCIÓN}

En el 2020, la enfermedad por COVID-19 progresó rápidamente a pandemia y se extendió en el Perú, a pesar de las medidas iniciales de contención ${ }^{(1)}$. El binomio madre-niño es par- 
ticularmente susceptible de responder desfavorablemente a enfermedades respiratorias por infecciones de beta coronavirus ${ }^{(2)} \mathrm{y}$ en infección por SARS-CoV-2 ${ }^{(3)}$. En la actual pandemia existen estudios que han reportado resultados variables en la mortalidad y morbilidad perinatal según distintos estudios ${ }^{(4,5)}$. Asimismo, existe la posibilidad de trasmisión vertical por su plausibilidad biológica de transmisibilidad transplacentaria, cuya detección en placenta y cordón umbilical es señalado en reportes de caso ${ }^{(6,7)}$; sin embargo, otros estudios evidenciaron resultados negativos a partir de muestra nasofaríngea del recién nacido procedente de madres con COVID-19, pudiendo existir limitaciones para su detección en tejidos de vía respiratoria superior ${ }^{\left({ }^{(8)}\right.}$. Es posible que la detección perinatal y complicaciones del SARS-CoV-2 en la madre y su recién nacido podrían estar condicionadas a la edad gestacional, momento de la infección y la carga viral ${ }^{(9)}$.

El presente estudio tuvo como objetivo describir los resultados materno-perinatales de pacientes con infección por SARS-CoV-2 identificadas antes del parto, en un hospital nivel III del Perú.

\section{EL ESTUDIO}

Se realizó un estudio descriptivo. La población de estudio fueron los recién nacidos de madres con COVID-19, atendidos en el Instituto Nacional Materno Perinatal (INMP) del Perú, entre el 1 de abril y el 30 de junio del 2020; se excluyeron aquellos en cuyas madres no fue posible la identificación de COVID-19 antes del parto. Ingresaron al estudio todos los recién nacidos de madres con resultado positivo para SARS-CoV-2 mediante prueba de reacción en cadena de polimerasa con transcriptasa inversa (RT-PCR, por sus siglas en inglés), a partir del hisopado faríngeo o nasal y procesados en el Instituto Nacional de Salud de Perú.

El estudio fue realizado en el INMP del Perú y debido a la pandemia por COVID-19 todas las gestantes atendidas en el servicio de emergencia se les realizó una prueba serológica para detectar la infección por el SARS-CoV-2. De acuerdo con el criterio médico, a algunas de ellas se les realizó la toma de hisopado faríngeo y nasal para RT-PCR, ya sea por antecedente epidemiológico o por prueba serológica negativa con clínica sospechosa antes de la atención del parto por vía vaginal o cesárea. Asimismo, se realizó la prueba de RT-PCR dentro de las primeras 12 horas de vida, a todos los recién nacidos de gestantes con COVID-19.

En el INMP se implementaron áreas diferenciadas de atención para el recién nacido, hijo de madre infectada, como sala de cuidados intermedios, sala de cuidados intensivos neonatales; los recién nacidos asintomáticos pasaron a sector de aislamiento a la que pasó también la madre, pero se mantuvieron separados hasta la toma de muestra para RT-PCR; luego se permitió la lactancia materna y el aislamiento conjunto con los cuidados de bioseguridad.

\section{MENSAJES CLAVE}

Motivación para realizar el estudio: Ante el contexto de COVID-19 en el Perú, damos a conocer los resultados materno-perinatales de gestantes con COVID-19 atendidas en un hospital nivel III del Perú.

Principales hallazgos: De 43 recién nacidos de madres con COVID-19, 21 procedían de gestantes que presentaron complicaciones obstétricas, principalmente rotura prematura de membranas y preeclampsia. Solo un recién nacido tuvo COVID-19, cinco fueron prematuros y cuatro tuvieron bajo peso al nacer. No hubo muertes maternas ni neonatales.

Implicancias: Se reporta uno de los primeros resultados perinatales de recién nacidos que procedieron de madres con COVID-19 así como un caso posible de transmisión vertical en el Perú.

Uno de los investigadores revisó los resultados de la prueba RT-PCR de la madre, un investigador diferente los resultados de RT-PCR del recién nacido; a partir de las fichas de pruebas RT-PCR en la oficina de Epidemiología y Salud Ambiental del INMP. Una vez identificados todos los recién nacidos que cumplían los criterios de selección, dos investigadores revisaron las historias clínicas de la madre y otros tres investigadores revisaron las de los recién nacidos. Se tuvo acceso a historias clínicas después de un mes del alta de los pacientes, tiempo en que las historias clínicas se mantuvieron aisladas como medida para evitar riesgo de transmisibilidad.

Se registró la edad materna previo al embarazo (16-18, 19-34 y 35 a más años); paridad indicado como nulípara (sin parto previo), primípara (primer parto previo) y multípara (mayor igual a 2 partos previos); control prenatal considerado como adecuado si presentó más de seis controles; síntomas respiratorios maternos (como tos, dolor de garganta, cefalea, fiebre, escalofrió y/o congestión nasal) presentes al ingreso hospitalario y/o al momento del parto; tipo de complicación en el embarazo; vía de parto por cesárea o parto vaginal; edad gestacional al momento del parto según fecha de última regla confiable o ecografía del primer trimestre, indicando prematuridad (menor a 37 semanas), a término (mayor igual a 37 semanas); peso del recién nacido medido en gramos, se consideró bajo peso al nacer (menor de $2500 \mathrm{~g}$ ), peso normal (2500 g a menor de $4000 \mathrm{~g}$ ) y macrosómico (mayor igual a 4000 g); sexo del recién nacido; depresión al nacer (puntaje de Apgar menor o igual a cinco) indicado al minuto y a los cinco minutos de vida; tipo de ingreso correspondiente a unidad de aislamiento, cuidados intermedios, cuidados intensivos, días de hospitalización; y condición al alta hospitalaria como fallecido o vivo. 
Los datos fueron digitados y procesados en Microsoft Excel 2013. Se realizó un análisis estadístico descriptivo, mediante distribución de frecuencias. Se codificaron los datos para asegurar la confidencialidad y el anonimato; solo los investigadores tuvieron acceso a ellos.

El estudio contó con la aprobación del Comité de Ética Institucional de Investigación del INMP (N. ${ }^{\circ}$ 21-2020-CIEI/ INMP) y tuvo la autorización correspondiente de la institución.

\section{HALLAZGOS}

Se identificaron 43 recién nacidos vivos procedentes de madres con COVID-19, se contó con los resultados de prueba RT-PCR de la madre y del recién nacido al momento del estudio. Un 60,5\% de los recién nacidos procedían de gestantes con edad entre 19 y 34 años, el control prenatal no adecuado fue $95,3 \%$, las gestantes nulíparas fueron el $44,2 \%$ y las primíparas el 30,2\% (Tabla 1).

El 48,8\% de gestantes presentaron complicaciones obstétricas, principalmente rotura prematura de membranas $(18,6 \%)$ y preeclampsia (11,6\%). El 93\% de recién nacidos procedían

Tabla 1. Características sociodemográficas y obstétricas de madres con COVID-19 de los recién nacidos atendidos en un hospital nivel III de Lima, Perú.

\begin{tabular}{|c|c|c|}
\hline Característica & $\mathbf{n}$ & $\%$ \\
\hline \multicolumn{3}{|c|}{ Edad materna (años) } \\
\hline $16-18$ & 5 & 11,6 \\
\hline $19-34$ & 26 & 60,5 \\
\hline 35 a más & 12 & 27,9 \\
\hline \multicolumn{3}{|l|}{ Control prenatal } \\
\hline No adecuado & 41 & 95,3 \\
\hline Adecuado & 2 & 4,7 \\
\hline \multicolumn{3}{|l|}{ Paridad } \\
\hline Nulípara & 19 & 44,2 \\
\hline Primípara & 13 & 30,2 \\
\hline Multípara & 11 & 25,6 \\
\hline \multicolumn{3}{|l|}{ Estado civil } \\
\hline Casada & 6 & 14,0 \\
\hline Conviviente & 24 & 55,8 \\
\hline Soltera & 13 & 30,2 \\
\hline \multicolumn{3}{|l|}{ Nivel educativo } \\
\hline Primaria & 2 & 4,7 \\
\hline Secundaria & 32 & 74,4 \\
\hline Superior & 9 & 20,9 \\
\hline \multicolumn{3}{|l|}{ Ocupación } \\
\hline Ama de casa & 40 & 93,0 \\
\hline Independiente & 2 & 4,7 \\
\hline Empleada & 1 & 2,3 \\
\hline
\end{tabular}

de madres con COVID-19 asintomáticas (Tabla 2). No hubo muertes maternas.

El $65,1 \%$ de embarazos culminó en parto por vía vaginal, el $16 \%$ de los recién nacidos presentó alguna morbilidad, el 11,3\% de neonatos fueron prematuros, el 9,3\% tuvo bajo peso al nacer, cuatro recién nacidos ingresaron a cuidados intermedios y dos casos a cuidados intensivos. La mayoría de los recién nacidos fueron dados de alta dentro de los dos o cuatro días de nacidos. Solo un neonato tuvo resultado positivo a RT-PCR en las primeras 12 horas de vida (Tabla 3).

El caso de neonato con RT-PCR positivo fue procedente de madre adolescente asintomática, nacido por parto vía vaginal, con 39 semanas de edad gestacional, puntaje Apgar de ocho al minuto y nueve a los cinco minutos, $3450 \mathrm{~g}$ de peso, ingresado a aislamiento, sin comorbilidad ni complicaciones y dado de alta a los tres días de nacido.

De los 42 neonatos con RT-PCR negativa, seis presentaron morbilidad que requirieron hospitalización (Tabla 3), cuatro en cuidados intermedios y dos en cuidados intensivos. De los cuatro ingresos a cuidados intermedios, dos fueron prematuros que presentaron Lúes congénita, ictericia y anemia; los otros dos casos fueron recién nacidos a término ingresados por gastritis química y mala tolerancia oral. De los dos neonatos ingresados a cuidados intensivos, uno fue de 37 semanas de edad gestacional, puntaje Apgar de tres al minuto y cinco al quinto minuto, $1978 \mathrm{~g}$ de peso, neumonía, sepsis, encefalopatía, acidosis metabólica y anemia; requirió ventilación mecánica durante cinco días, presión positiva continua en las vías aéreas (CPAP) durante cuatro días y dado de alta a los 19 días de nacido. Mientras que el segundo caso que ingresó

Tabla 2. Características clínicas y complicaciones obstétricas de madres con COVID-19 de los recién nacidos atendidos en un hospital nivel III de Lima, Perú.

\begin{tabular}{lcc}
\hline Característica & n & $\%$ \\
\hline Síntomas & 40 & 93,0 \\
$\quad$ No & 3 & 7,0 \\
$\quad$ Sí & & \\
Complicaciones en el embarazo & 21 & 48,8 \\
$\quad$ Complicaciones obstétricas & 22 & 51,2 \\
$\quad$ Sin complicaciones & & \\
Tipo de complicación & 1 & 2,3 \\
$\quad$ Amenaza de aborto & 4 & 9,3 \\
Trabajo de parto disfuncional & 5 & 11,6 \\
Preeclampsia & 2 & 4,7 \\
Sufrimiento fetal & 8 & 18,6 \\
Ruptura prematura de membranas & 1 & 2,3 \\
RCIU & 22 & 51,2 \\
Sin complicaciones & &
\end{tabular}

RCIU: retardo de crecimiento intrauterino. 
Tabla 3. Resultados perinatales en recién nacidos de madres con COVID-19 atendidos en un hospital nivel III de Lima, Perú.

\begin{tabular}{|c|c|c|}
\hline Característica & $\mathbf{n}$ & $\%$ \\
\hline \multicolumn{3}{|l|}{ Vía de parto } \\
\hline Cesárea & 15 & 34,9 \\
\hline Vaginal & 28 & 65,1 \\
\hline \multicolumn{3}{|l|}{ Sexo } \\
\hline Femenino & 19 & 44,2 \\
\hline Masculino & 24 & 55,8 \\
\hline \multicolumn{3}{|l|}{ Apgar 1 min } \\
\hline Depresión ( $\leq 5$ puntos) & 2 & 4,7 \\
\hline Sin depresión ( $\geq 6$ puntos) & 41 & 95,3 \\
\hline \multicolumn{3}{|l|}{ Apgar 5 min } \\
\hline Depresión ( $\leq 5$ puntos) & 1 & 2,3 \\
\hline Sin depresión ( $\geq 6$ puntos) & 42 & 97,7 \\
\hline \multicolumn{3}{|l|}{ Peso } \\
\hline Bajo peso & 4 & 9,3 \\
\hline Peso normal & 35 & 81,4 \\
\hline Macrosómico & 4 & 9,3 \\
\hline \multicolumn{3}{|l|}{ Edad gestacional } \\
\hline Prematura & 5 & 11,6 \\
\hline A término & 38 & 88,4 \\
\hline \multicolumn{3}{|l|}{ RT-PCR en recién nacido } \\
\hline Positivo & 1 & 2,38 \\
\hline Negativo & 42 & 97,7 \\
\hline \multicolumn{3}{|l|}{ Morbilidad neonatal } \\
\hline Sí & 6 & 13,95 \\
\hline No & 37 & 86,05 \\
\hline \multicolumn{3}{|l|}{ Neumonía en recién nacido } \\
\hline Sí & 2 & 4,7 \\
\hline No & 41 & 95,3 \\
\hline \multicolumn{3}{|l|}{ Días de hospitalización } \\
\hline \multicolumn{3}{|l|}{ En aislamiento (días) } \\
\hline 1 a 2 & 26 & 60,45 \\
\hline 3 a 4 & 11 & 25,56 \\
\hline \multicolumn{3}{|c|}{ En cuidados intermedios (días) } \\
\hline 3 & 1 & 2,3 \\
\hline 8 & 1 & 2,3 \\
\hline 9 & 1 & 2,3 \\
\hline 16 & 1 & 2,3 \\
\hline \multicolumn{3}{|l|}{ En cuidados intensivo } \\
\hline 13 & 1 & 2,3 \\
\hline 19 & 1 & 2,3 \\
\hline
\end{tabular}

a la unidad de cuidados intensivos se trató de un prematuro de 34 semanas de edad gestacional, puntaje de Apgar de ocho al minuto y nueve al quinto minuto, $2450 \mathrm{~g}$ de peso, presentó neumonía, sepsis, choque séptico, coagulación intravascular diseminada, acidosis metabólica e ictericia; requirió ventilación mecánica durante cuatro días, CPAP por tres días y cánula binasal durante dos días y fue dado de alta a los 13 días de vida. No hubo muertes neonatales.

\section{DISCUSIÓN}

El estudio permite observar que de los 43 recién nacidos de madres con COVID-19 solo uno presentó resultado positivo de RT-PCR a partir de muestra nasofaríngea. Los recién nacidos en el estudio procedieron con mayor frecuencia de madres con COVID-19 asintomáticas. Entre las complicaciones obstétricas se encontraron rotura prematura de membranas $(18,6 \%)$ y preeclampsia $(11,6 \%)$ mientras que entre las comorbilidades de los recién nacidos se encontró prematuridad (11,3\%), bajo peso al nacer $(9,3 \%)$ y sepsis con neumonía que requirió ventilación mecánica $(4,7 \%)$.

Un cribado rutinario en la ciudad de Nueva York para SARS-CoV-2 mediante RT-PCR antes del parto identificó un $88 \%$ de gestantes asintomáticas, y los casos sintomáticos fueron leves ${ }^{(10)}$. Similares resultados se reportaron en un estudio realizado en el INMP de Perú que aplicó pruebas rutinarias de serología para SARS-CoV-2 ${ }^{(11)}$. Un estudio multicéntrico en América Latina encontró 68\% de madres infectadas asintomáticas, $89 \%$ de las madres sintomáticas presentaron sintomatología leve o moderada y el 2,3\% ingresaron a terapia intensiva ${ }^{(12)}$. Estas diferencias porcentuales pueden deberse al tipo de estudio, tipo de prueba y diferencias en las poblaciones, a pesar de ello sugieren mayormente una elevada frecuencia de gestantes asintomáticas y concuerdan con el hallazgo de síntomas respiratorios leves. Sin embargo, existe variabilidad clínica en la madre, lo cual debe considerarse al momento de evaluar las condiciones del recién nacido.

Las principales complicaciones obstétricas observadas fueron rotura prematura de membranas y preeclampsia, similar a lo encontrado en estudios previos que utilizaron la prueba RT-PCR para la detección de SARS-CoV-2 ${ }^{(3)}$ así como en estudios que utilizaron pruebas serológicas en gestantes ${ }^{(11)}$. La frecuencia de preeclampsia observada en el presente estudio $(11,6 \%)$ estaría dentro de los hallazgos reportados en estudios previos a la pandemia por COVID-19, donde varían entre un $2 \%$ y $12 \%{ }^{(13)}$. Sin embargo, la frecuencia de rotura prematura de membranas $(18,6 \%)$ es mayor a los hallazgos en la población antes de la pandemia por COVID-19, donde varía entre $8 \%$ al $10 \%{ }^{(14)}$. No obstante, la variabilidad observada en las complicaciones puede corresponder a la carga viral durante el embarazo ${ }^{(15)}$. Sin embargo, estos estudios son descriptivos, por lo cual, no cuentan con un análisis causal para apoyar un riesgo asociado a la infección por SARS-CoV-2.

Se observó que el 11,3\% de los recién nacidos fueron prematuros y el 9,3\% presentó bajo peso al nacer. En una serie 
histórica en este mismo hospital durante los años previos a la pandemia por COVID-19, se encontró que la prevalencia de nacimientos prematuros y de recién nacidos con bajo peso al nacer fue alrededor de $8,5 \%$ y 2,2\% respectivamente ${ }^{(16)}$. Por otro lado, en el Perú la tasa de nacimientos prematuros a nivel nacional para el 2019 fue del 7\% ${ }^{(17)}$. Estas diferencias pueden deberse a la atención especializada de la institución, que es un centro de referencia nacional de atención especializada materno-perinatal. Cifras más altas como $41,1 \%$ de prematuridad fue reportada en una revisión sistemática de estudios retrospectivos, que incluía reportes de casos de infección por COVID-19 ${ }^{(2)}$. Sin embargo, se deben considerar los partos pretérminos iatrogénicos que llegan a alcanzar cifras del 80\% de los partos, en donde el $48 \%$ se debió a infección materna de SARS-CoV-2, solo el $14 \%$ por compromiso fetal y el $18 \%$ por otras causas obstétricas ${ }^{(18)}$. En el presente estudio la atención del parto obedeció a la condición obstétrica y no solo a la detección de infección por SARS-CoV-2.

En el estudio no se encontraron muertes neonatales; no obstante, dos recién nacidos ingresaron a cuidados intensivos y cuatro a cuidados intermedios debido a comorbilidades perinatales, con prueba RT-PCR negativa. Una revisión sistemática encontró un índice de muerte perinatal del $7 \%{ }^{(2)}$, otro estudio reportó una muerte entre 108 casos y una baja morbilidad ${ }^{(4)}$. Los casos ingresados a cuidados intensivos o intermedios fueron los que requirieron mayor tiempo de hospitalización debido a prematuridad, dos casos de neumonía, sepsis, ictericia, acidosis metabólica y un caso de encefalopatía. Sin embargo, la mayoría de recién nacidos tuvieron un peso normal, incluido el caso de recién nacido con RT-PCR positiva, y fueron dados de alta dentro de los tres días de nacido sin complicaciones.

Se observó solo un caso de recién nacido con RT-PCR positiva para SARS-CoV-2 dentro de las 12 horas de vida, lo cual podría sugerir una trasmisión vertical. Estudios previos han descrito que la trasmisión placentaria viral podría darse por vía hematógena ${ }^{\left({ }^{19)}\right.}$. Para confirmar una trasmisión vertical se debe detectar el ARN viral en el cordón umbilical, la sangre neonatal en las primeras doce horas y la placenta o líquido amniótico antes de la ruptura de membranas ${ }^{(20)}$. Existen reportes de casos de trasmisión placentaria mediante el estudio de muestras biológicas, en donde la madre y el recién nacido presentaron algún tipo de complicación ${ }^{(6,7)}$. A pesar de la limitada evidencia sobre trasmisión vertical, se ha reportado que existe un $4 \%$ de incidencia de infección en el posparto y los recién nacidos con RT-PCR positivo con frecuencia son asintomáticos, según hallazgos de una revisión sistemática en base a reportes de casos ${ }^{(15)}$.

En cuanto a las limitaciones del estudio, la información retrospectiva podría representar amenaza a la validez, para disminuir esto, la recolección de la información de la madre y de su recién nacido se realizó de forma independiente, así como la disponibilidad de los resultados de laboratorio de la prueba de RT-PCR; el tamaño de la muestra fue pequeño; y al momento de realizar el estudio se desconocía el tiempo de infección por SARS-CoV-2 hasta el momento del parto, así como la carga viral en la madre previo al parto.

Se concluye que las madres con COVID-19 de los recién nacidos incluidos en el estudio fueron asintomáticas en su mayoría y presentaron como complicaciones rotura prematura de membranas y preeclampsia. Los recién nacidos presentaron resultado negativo de RT-PCR en su mayoría, siendo la morbilidad más frecuente en ellos prematuridad, bajo peso al nacer, sepsis y neumonía que requirió ventilación mecánica. Solo uno de los recién nacidos presentó un resultado positivo de RT-PCR a COVID-19 y no presentó comorbilidades. Sin embargo, la evidencia es limitada y se requiere estudios perinatales de corto y a largo plazo.

Contribuciones de autoría: Todos los autores participaron en la concepción y diseño del artículo, y en la recolección de datos. CDA, RHP, MES realizaron el análisis estadístico de datos. Todos los autores participaron en la interpretación de los datos, redactaron el artículo, hicieron la revisión crítica del manuscrito, aprobaron su versión final y se hacen responsables de los contenidos del manuscrito.

Financiamiento: Autofinanciado.

Conflictos de interés: Los autores declaran no presentar conflicto de intereses.

\section{REFERENCIAS BIBLIOGRÁFICAS}

1. Espinola-Sánchez M, Racchumí-Vela A, Sanca-Valeriano S, Espinola-Sánchez S, Arango-Ochante P, Saldaña-Díaz C, et al. Pandemia de Covid-19y efecto de medidas de contención en población peruana: Un modelamiento matemático SIR. Revista Del Cuerpo Médico Del HNAAA. 2020;13(2): 110-115. doi: 10.35434/rcmhnaaa.2020.132.656.

2. Di Mascio D, Khalil A, Saccone G, Rizzo G, Buca D, Liberati M, et al. Outcome of coronavirus spectrum infections (SARS, MERS, COVID-19) during pregnancy: a systematic review and meta-analysis. Am J Obstet Gynecol. 2020;2:100107. doi: 10.1016/j.ajogmf.2020.100107.

3. Dashraath P, Wong JLJ, Lim MXK, Lim LM, Li S, Biswas A, et al. Coronavirus disease 2019 (COVID-19) pandemic and pregnancy. Am J Obstet Gynecol. 2020; 222:521-31. doi: 10.1016/j.ajog.2020.03.021.
4. Huntley BJF, Huntley ES, Di Mascio D, Chen T, Berghella V, Chauhan SP. Rates of Maternal and Perinatal Mortality and Vertical Transmission in Pregnancies Complicated by Severe Acute Respiratory Syndrome Coronavirus 2 (SARS-Co-V-2) Infection: A Systematic Review. Obstetrics \& Gynecology. 2020;136:303-312. doi: 10.1097/ AOG.0000000000004010.

5. Zaigham M, Andersson O. Maternal and perinatal outcomes with COVID-19: A systematic review of 108 pregnancies. Acta Obstet Gynecol Scand. 2020;99:823-9. doi: 10.1111/aogs.13867.

6. Vivanti AJ, Vauloup-Fellous C, Prevot S, Zupan V, Suffee C, Do Cao J, et al. Transplacental transmission of SARS-CoV-2 infection. Nat Comm. 2020;11:3572. doi: 10.1038/s41467-020-17436-6. 
7. Penfield CA, Brubaker SG, Limaye MA, Lighter J, Ratner AJ, Thomas $\mathrm{KM}$, et al. Detection of SARS-COV-2 in Placental and Fetal Membrane Samples. Am J Obstet Gynecol. 2020:100133. doi: 10.1016/j. ajogmf.2020.100133.

8. Limay-Ríos OA, Dávila-Aliaga C, Álvarez-Carrasco RI, Espinola-Sánchez M. Transmisión perinatal de SARS-CoV-2: necesidad de estudio ante posible infección congénita. Rev Colomb Obstet Ginecol. 2020;71(3): 220-221. doi: 10.18597/rcog.3545.

9. Auriti C, Rose DUD, Tzialla C, Caforio L, Ciccia M, Manzoni P, et al. Vertical Transmission of SARS-CoV-2 (COVID-19): Are Hypotheses More than Evidences?. Am J Perinatol 2020;37:S31-8. doi: 10.1055/s-0040-1714346.

10. Sutton D, Fuchs K, D’Alton M, Goffman D. Universal Screening for SARSCoV-2 in Women Admitted for Delivery. N Engl J Med. 2020;382:2163-4. doi: 10.1056/NEJMc2009316.

11. Guevara-Ríos E, Espinola-Sánchez M, Carranza-Asmat C, Ayala-Peralta F, Álvarez-Carrasco R, Luna-Figueroa A, et al. Anticuerpos anti-SARSCOV-2 en gestantes en un hospital nivel III de Perú. Rev Peru Ginecol Obstet. 2020;66(3). doi: 10.31403/rpgo.v66i2259.

12. Augusto Sola, Susana Rodríguez, Marcelo Cardetti, Carmen Dávila. COVID-19 perinatal en América Latina. Rev Panam Salud Públ. 2020;44e:47. doi: 10.26633/RPSP.2020.47.

13. Sánchez SE. Actualización en la epidemiología de la preeclampsia: update. Rev Peru Ginecol Obstet. 2014; 60(4):309-320. doi: 10.31403/rpgo.v60i155.

14. American College of Obstetricians and Gynecologists. Practice Bulletin No. 188 Summary: Prelabor Rupture of Membranes. Obstet Gynecol. 2018;131:187-9. doi: 10.1097/AOG.0000000000002449.
15. Walker KF, O’Donoghue K, Grace N, Dorling J, Comeau JL, Li W, et al. Maternal transmission of SARS-COV-2 to the neonate, and possible routes for such transmission: a systematic review and critical analysis. BJOG: An International Journal of Obstetrics \& Gynaecology. 2020.127(11):13241336. doi: 10.1111/1471-0528.16362.

16. Fano-Sizgorich D, Ayala-Peralta F, Carranza-Asmat C, Guevara-Ríos E, Luna-Figueroa A. Resultados preliminares del análisis de bajo peso al nacer, nacimiento pretérmino y pequeño para la edad gestacional, reportados en la base de datos del Instituto Nacional Materno Perinatal durante los años 2012-2017. Rev Peru Investig Matern Perinat. 2018;7(1): 9-17. doi: 10.33421/inmp.2018104.

17. Ministerio de Salud de Perú. Centro Nacional de Epidemiología, Prevención y Control de Enfermedades. Boletín Epidemiológico del Perú SE 462019 [Internet]. Perú. 2019 [citado el 14 de octubre de 2020]. Disponible en:https://www.dge.gob.pe/portal/docs/vigilancia/boletines/2019/46.pdf.

18. Guan W, Ni Z, Hu Y, Liang W, Ou C, He J, et al. Clinical Characteristics of Coronavirus Disease 2019 in China. New England Journal of Medicine. 2020;382:1708-20. doi: 10.1056/NEJMoa2002032.

19. Pereira L, Maidji E, McDonagh S, Tabata T. Insights into viral transmission at the uterine-placental interface. Trends Microbiol. 2005;13:164-74. doi: 10.1016/j.tim.2005.02.009.

20. Patané L, Morotti D, Giunta MR, Sigismondi C, Piccoli MG, Frigerio $\mathrm{L}$, et al. Vertical transmission of COVID-19: SARS-CoV-2 RNA on the fetal side of the placenta in pregnancies with COVID-19 positive mothers and neonates at birth. Am J Obstet Gynecol. 2020:100145. doi: 10.1016/j. ajogmf.2020.100145. 